\title{
DESOBEDIENCIA DE LA RAZÓN: EL CUERPO Y SUS PLACERES EN UNA EXQUISITA NOVELA DE ARTURO ARIAS, SOPA DE CARACOL
}

Oriel María Siu

\section{(c)}

Esta obra está bajo una licencia Creative Commons

Reconocimiento-No Comercial-Sin Obra Derivada 



\title{
DESOBEDIENCIA DE LA RAZÓN: EL CUERPO Y SUS PLACERES EN UNA EXQUISITA NOVELA DE ARTURO ARIAS, SOPA DE CARACOL
}

\author{
DISOBEDIENCE OF REASON: THE BODY AND ITS PLEASURES IN A \\ DELICIOUS NOVEL BY ARTURO ARIAS, SOPA DE CARACOL
}

\begin{abstract}
RESUMEN
El presente artículo examina cómo la risa, la palabra, el placer, los desbordes de la emoción y los sentidos, el travestismo y el deseo aparecen en la novela Sopa de caracol (2002) de Arturo Arias como zonas no normables por el poder y su colonialidad. Son sitios donde poderes otros trabajan de manera distinta a lo usualmente visto en textualidades de la diáspora y la posguerra centroamericana. En esta novela el poder interroga e invierte modelos heterárquicos del poderactuando, en primera instancia, en la ausencia de patrones que perpetúan moldes racializadores de superioridad/inferioridad de la modernidad/colonialidad. Actúa además, desde los parámetros de una corpo-política, perspectiva a partir de la cual se subvierten prácticas de poder epistémicas que insisten en separar al cuerpo de la razón. Estas otras jurisdicciones no-normables por el poder y su colonialidad en la novela Sopa de caracol son el enfoque del presente trabajo.

Palabras clave: Literatura centroamericana, diáspora, colonialidad, desobediencia epistémica, identidad.
\end{abstract}

\begin{abstract}
This article examines how laughter, language, pleasure, the overflow of emotions and the senses, travestism, and desire appear in Arturo Arias' Sopa de caracol (2002) as ungovernable zones where power and coloniality cannot reign. These are sites where power works alternatively, differing from what is usually seen within Central American diasporic and post-war textualities. In this novel power interrogates and inverts heterarquical models of power primarily acting in the absence of patterns that perpetuate the racialized superiority/inferiority structures posed by modernity/coloniality. Moreover, in this novel power acts within the parameters of a corpo-politica, perspective from which epistemic practices of power that separate body from reason become subverted. These ungovernable jurisdictions and zones are the focus of the present article.

Keywords: Central American literatures, diaspora, coloniality, epistemic disobedience, identity.
\end{abstract}

La risa, la palabra, el placer, los desbordes de la emoción, el amor, el travestismo, la fantasía y el deseo, aparecen en la novela de Arturo Arias, Sopa de caracol (2002), como zonas no normables por el poder y su colonialidad. Son sitios donde modelos heterárquicos,

Dra. Oriel María Siu. University of Puget Sound. Latina/o Studies Director and Assistant Professor. Hispanic Studies Department. Estados Unidos.

Correo electrónico: osiu@pugetsound.edu

Recepción: 10- 06- 2015

Aceptación: 03- 08- 2015 
patriarcales y racializadores del poder se ven interrogados e invertidos, evidenciando en vez una ausencia de patrones perpetuadores del molde superioridad/inferioridad de la modernidad/ colonialidad. Estas zonas además se enuncian desde los parámetros de una corpo-política, perspectiva a partir de la cual se subvierten prácticas de poder epistémicas que han insistido en separar a la razón del cuerpo, y en vez se enuncian desde un cuerpo racializado de localidad, memoria y experiencia específica; desde un cuerpo arraigado en historias locales; un cuerpo que además tiene sus propios deseos y fantasías y que practica sus propias desobedientes sexualidades. Estas otras jurisdicciones no-normables por el poder en la novela Sopa de caracol son el enfoque del presente trabajo. En estas zonas argumento, se efectúan políticas de poder capaces de transgredir lo que Giorgio Agamben ha llamado un estado de excepción, la indiferenciación, y el estatus homo sacer, en este caso, de los seres desagenciados y diaspóricos en esta susodicha posguerra centroamericana.

Ya en otras instancias he articulado la manera en que mucha de la novelísitca de la diáspora y la ex-militancia centroamericana devela a sujetos explotados y disciplinados por el poder. ${ }^{1}$ Este poder los invisibiliza, haciendo del acto de migrar y establecer comunidad en lugares como Estados Unidos, una experiencia caracterizada por la constante del desempleo, la precariedad económica, la ausencia de la esperanza en el futuro, y de manera tanto figurada como concreta, la normalización de la muerte. En esas otras textualidades de la diáspora, ese poder disciplinario también organiza y dictamina los actos de los personajes. Como cuerpos disciplinados, éstos usualmente se ven en la perpetuación de prácticas heteronormativas, clasistas, racistas, marginalizadoras y excluyentes; es decir, se ven en la reproducción de prácticas infundidas de colonialidad y su poder. Sopa de caracol tiene como uno de sus objetivos principales visibilizar y cuestionar tales prácticas, revertirlas y proponer en vez su desarticulación epistémica y física.

Escrita entre 1993 y 1997, entre San Francisco y Madrid, entre la guerra y la posguerra guatemalteca, ${ }^{2}$ y entre las circunstancias del autoexilio del propio escritor, Sopa de caracol es una novela compleja. Tanto a nivel lingüístico como a nivel de trama, forma, narración, contenido, referencialidad intratextual y extra textual, la novela de Arias se construye y a la vez destruye como textualidad del exilio; como textualidad de la diáspora; como textualidad de la posguerra y como textualidad centroamericana. Cabe y a la vez no cabe dentro de tales categorías puesto que trasciende constantemente sus propias categorizaciones y temáticas, sobrepasando así la experiencia de una individualidad puramente centroamericana.

Estructurada en forma de menú, cada capítulo de Sopa lleva el subtítulo de cada uno de los platillos que el personaje principal, Rodrigo, un ex-revolucionario guatemalteco de más de cuarenta años que radica en San Francisco, California, le ofrece a sus invitados especiales en una de esas noches que no se olvidan. La cena se la ofrece a unas "ciertas relaciones muy suyas" de quienes necesita cartas de apoyo para evitar el desempleo en la universidad donde trabaja (Arias, 2002, p. 9). "Un vulgar académico de segunda en una universidad estadounidense de tercera dedicado a perseguir niñitas de 20 años para ejercitar ese concepto conocido en Guatemaya como «meter mano»", nuestro narrador ha recién manoseado a una de sus estudiantes (Arias, 2002, p. 9). Ella lo ha denunciado ante las autoridades de la institución académica, motivo por el cual Rodrigo se halla en problemas con la administración y pidiendo el apoyo de sus colegas que ahora lo acompañan en la cena.

La cena está repleta de momentos lúdicos, de música, bebidas embriagantes, y platillos exquisitos; lo mejor de la cocina garífuna, guatemalteca y europea que el anfitrión Rodrigo ha 
podido preparar para sus invitados. La noche incluye también historias entretenidas de derrotas en el amor y la guerra que el anfitrión comparte sobre su vida de militante en la guerrilla guatemalteca durante la década de los 80 , así como también anécdotas sobre su presente de hombre solitario en esa ciudad californiana. Habiendo sido estas historias expuestas en forma de monólogo, hacia el final de la novela (y la cena) los invitados se cansan de escuchar las historias del personaje. Es ahí cuando las invitadas deciden travestirse para finalizar la noche con una escena que gravitará entre el placer sexual y una despiadada violación sexual al anfitrión. A pesar de disfrutar ciertos momentos de la penetración de su cuerpo, en las últimas líneas de la novela sabemos que el narrador no se encuentra bien ni física ni emocionalmente después de esta última escena. El mismo queda solicitando el silencio de sus invitados (y los lectores), sintiendo y sufriendo dolor y pidiendo que lo dejen solo:

\footnotetext{
No se paseen por allí como Pedro por su casa. [...] No recojan la basura. No apaguen la música. No hagan ruido, me estalla la cabeza. No se acaben mis tylenoles.[...] No, no, nada, no, ya no, no, ya no. [...] Cierren al salir. Mis pensamientos giran. Todo gira. Me callo. Silencio, silencio ya. (Arias, 2002, p. 281)
}

La novela termina ahí, en el silencio suscitado por el narrador y otorgado por los invitados que se ven forzados a dejar la casa del narrador cuando el mismo les ha pedido que se vayan.

Optando por inscribirse dentro de un proyecto no sólo literario sino además epistémico, Sopa de caracol resulta siendo una novela no fácilmente digerible (gustable, bonita, o como se prefiera llamar), ni mucho menos de entretenimiento o consumo cotidiano. Por un lado, el lenguaje empleado es en gran parte figurado y desbordante. A veces él mismo cambia del español al inglés, y en la mayor parte de los casos al portugués, incorporando además frases en francés, lírica musical en garífuna y muchas veces hasta palabras combinadas o inventadas por el mismo narrador. Los signos de interrogación además se interponen en la narrativa sin atender a los mandatos gramaticales de la Real Academia, instándonos desde una perspectiva visual, a experimentar una lectura colmada de obstáculos, silencios e interrupciones. Por medio de una supresión o adición de letras en las palabras además, el lenguaje muchas veces acarrea su propio ritmo, afectando el marcador temporal de nuestra lectura y añadiéndole aún otra dimensión a los efectos sensoriales que el texto logra provocar. A través de su desobediencia lingüística, el lenguaje de esta sopa profana las estructuras impuestas por los reglamentos gramaticales. En un sentido figurado y si pensamos la gramática como una estructura de poder, podríamos decir que la profanación lingüística en esta sopa en sí sugiere una herramienta de desarticulación del poder, simbolizada claramente por esa estructura del lenguaje que la novela constantemente transfigura y desajusta.

Por otro lado, la estructura de la narración es todo menos lineal o lo que pudiera llamarse coherente, ya que como lo anuncia el mismo narrador, la verdad es que "uno se alarga al contar. Peor nosotros que somos enredados, barrocos, anti-cartesianos e innatamente pusmodernos" (Arias, 2002, p. 33). En esta Sopa de caracol encontraremos pues, relatos de episodios fragmentados, retomados algunos en capítulos posteriores o muchos dejados simplemente sin terminar. Ello porque el personaje habla conforme a los procesos operativos de su memoria y el acto de recordar, resultando a primera lectura en una narración que al lector le podrá parecer caótica o difícil de seguir. Aún así, a pesar de exteriorizar ciertos desórdenes narrativos y linguísticos, tal y como nos dice el propio Rodrigo, "Créanlo o no esta narración tiene su logiquilla, si es que podemos suponer que monos tercer mundistas pueden ser lógicos aunque carezcan de madurez kantiana" (Arias, 2002, p. 33). 
La característica del texto que aquí más interesa enfatizar entonces -la que le brinda sentido a esa "logiquilla" y la que termina de proyectar una propuesta de desobediencia cartesiana-, es el lugar epistémico de su enunciación; ese lugar que carece de "madurez kantiana" y que acarrea su propia lógica.

\section{Sobre esa mayor estructuración cartesiana}

La enunciación del narrador de Sopa de caracol proviene, en parte, de una rotunda negación a la racionalización cartesiana, representada dentro de la novela por los preceptos y las conductas de la guerrilla guatemalteca. De acuerdo a nuestro narrador, esa organización de izquierda a la que él perteneció en Guatemala durante la década de los 80 actuó bajo un ordenamiento lineal, desarrollista, impositivo, heteronormativo, exclusionario y disciplinario. Por medio de una serie de prácticas de poder, la guerrilla guatemalteca fijó formas unilaterales de conducta. Impuso reglamentos que objetaron formar y controlar cuerpos para beneficio del proyecto de nación que esta misma organización formuló a partir de una retórica revolucionaria. Tales reglamentos se manifestaron en un sentido tanto físico como figurado, invisibilizándose en el proceso epistemologías otras de organización social e invisibilizándose a subjetividades otras que no encajaran dentro de los preceptos del "hombre nuevo" a los que la sociedad centroamericana y revolucionaria en formación debía aspirar. Todos estos modelos impositivos de conducta representan dentro del marco simbólico del texto, esa mayor estructuración cartesiana.

A lo largo de la cena, Rodrigo también nos deja en claro otro elemento del fallo revolucionario. Según nuestro narrador, al igual que el proyecto colonizador y el proyecto decimonónico de nación del siglo XIX, la guerrilla de Guatemala también apoyó la desaparición/muerte del sujeto hecho otro de manera diferenciada y hasta apadrinó la desaparición de aquellos sujetos adscritos al mismo proyecto revolucionario. El famoso lema "Patria o Muerte, ¡Venceremos!” y la frase "el costo social de la revolución” que se repitieron una y otra vez en el ámbito centroamericano de guerras son para Rodrigo frases representativas de aquella postura.

Durante el período revolucionario el mismo Rodrigo perdió a dos amantes por quienes había llegado a sentir gran afecto; de una de ellas incluso hasta se había llegado a "enamorar". Mientras una de ellas, V/V, militaba -siendo por consecuencia de su militancia desaparecida en Guatemala, la otra amante, Valéria, carioca, sin saberlo fue utilizada como carnada por Rodrigo en una de sus misiones revolucionarias en el Brasil. El personaje de Valéria es emblemático pues evidencia la utilización promovida por el movimiento guerrillero: su cuerpo y sexualidad fueron determinadamente objetivizados por Rodrigo para poder éste atrapar a un enemigo de guerra que se escondía en Rio de Janeiro. A lo largo de la cena Rodrigo reconoce su propia participación en la objetivización de estas mujeres y desaprueba de ella; al relatarnos sus experiencias con V/V y Valéria reconoce la forma en que él reprodujo conductas marginalizadoras al formar parte de la guerrilla guatemalteca. Pero el personaje de Valéria es también simbólico en otro sentido; ella representa la manera en que la guerrilla llegó a afectar incluso a personas no-adscritas al proyecto revolucionario. Al saberse abandonada por Rodrigo -y ya sin la posibilidad de poder escapar su precaria situación económica en Brasil- Valéria opta por el suicidio. Muere sin haber puesto pie en Centroamérica, sin conocimiento alguno de la Revolución guatemalteca, y sin consciencia alguna de su sometimiento y objetivización por esa misma organización. Su muerte apunta hacia la actitud indiferenciadora de la Guerrilla; 
y por extensión, hacia la actitud indiferenciadora de la eurocéntrica colonialidad que en Centroamérica haya históricamente profesado la muerte.

Son estas las muertes que según Rodrigo el criterio guerrillero explicó (o consintió a) bajo el uso de la "frasesilla", "el costo social de la revolución" (Arias, 2002, p. 107). Con respecto a la frase, en la cena Rodrigo reflexiona:

\footnotetext{
En ella se resumían todos los muertos, desaparecidos, torturados, masacrados. Pero también éramos nosotros que mentíamos, engañábamos, fingíamos, utilizábamos, instrumentalizábamos a cualquiera y especialmente a las personas que más queríamos en aras de «la causa». [La guerrilla] nos deshumanizaba fundamentalistamente. Mataba los sentimientos. Nos volvíamos los robochafas de la izquierda. Estábamos comiendo frijolitos y nos tirábamos pedos de pollo. (Arias, 2002, pp. 107-108)
}

En Sopa de caracol Rodrigo insiste en exponer esta apología de muerte, invisibilización e instrumentalización asentida por la izquierda. Por medio de visibilizar y articular esta realidad, denuncia la objetivización de las personas convertidas en eliminables por el estado de excepción histórico centroamericano, en particular, por la guerrilla misma. Aunque Rodrigo haya sido partícipe de su instrumentalización, él ahora toma el espacio de esta novela para reflexionar sobre la misma, optando por desarticularla y compartirla con quienes lo acompañan en la cena, y con nosotros, sus lectores. Se trata pues, de una consciente reflexión sobre las formas en que la colonialidad del poder al centro del paradigma revolucionario centroamericano manipuló y usó la vida de sus sujetos, algo que no vemos ocurrir en muchos otros textos sobre la exmilitancia centroamericana.

Esta insistencia de Rodrigo en develar estas prácticas del poder radica no sólo en la aceptación y articulación de esa realidad sino también en la invalidación de la lógica emancipatoria misma que la justificó. Como el mismo Rodrigo lo articula hacia el final de la cena, su mayor propósito al hablar es exponer "las derruidas racionalizaciones que empujaban su lógica hasta barroquizar la cerebralidad, la irracionalidad de la razón” (Arias, 2002, p. 276). En esta consciencia, la crítica que el ex-militante va montando a lo largo de Sopa de caracol -los señalamientos del fallo revolucionario, sus incongruencias y tecnologías implementadas de muerte- no es una crítica que se limite a los designios de la guerrilla guatemalteca, sino que se extiende a la estructura epistémica misma que había convertido a la guerrilla y sus sustentos en una opción "lógica". La de Rodrigo es una crítica a la estructura epistémica que había convertido a la guerrilla en el modelo de emancipación legítimo y "racional" a seguir en el ámbito centroamericano de guerra. El propósito de Rodrigo es por lo tanto, como el mismo lo acierta, "Romper la dependencia de la razón" (Arias, 2002, p. 228); cuestionar y, como lo veremos ahora, subvertir los sustentos epistémicos que infundieron a esa "razón" de valor y autenticidad por medio del cuerpo y la corpopolítica.

\section{El cuerpo y sus placeres en la desvalidación del ego-cógito cartesiano}

Siendo la mente el signo por excelencia del ego-cógito cartesiano, en Sopa de caracol ella es reubicada a un segundo plano enunciativo. A lo largo de la cena, tanto dentro de las anécdotas que Rodrigo relata como en la cena misma, los goces del cuerpo humano aparecen como entidades capaces de transgredir los soliloquios izquierdistas (y racionalistas) que durante el período revolucionario impidieron articulaciones otras del poder. Los placeres que el cuerpo puede experimentar -la risa, el sabor, la estimulación erótica, el sexo y otras formas de relaciones- aparecen aquí como zonas no sólo desarticuladoras de lo cartesiano, sino además promotoras de otras dinámicas de relación social e (inter)subjetivas. Aparecen por lo 
tanto, como promotoras de otras dinámicas de poder con objetivos radicalmente diferentes a los de controlar, instrumentalizar y manipular sustentados por la guerrilla.

Por ejemplo, al relatar sobre los principios revolucionarios que durante el período guerrillero Rodrigo tenía que memorizar, el personaje declara:

\begin{abstract}
Para no tronar recitaba masticadamente como las monjitas los cinco principios y las diez ideas de nuestra organización para protegerme de la lluvia o de la muerte. Pero por mucho que medio recordara líneas tales como "la guerra revolucionaria no es para nosotros solamente la vía de la revolución, sino que es la estrategia global de la lucha revolucionaria por la toma del poder, porque concebimos que en esta guerra, si bien los destacamentos militares juegan un papel decisivo y fundamental, deben ser complementados con la organización política y amplia de las masas", las imágenes que hinchaban mi desorbitada cabeza eran las de las frutales piernas musgosas de la Valéria, la cabellera renegrida en los pezones violáceos que me encantaba morder y verlos triplicarse en tamaño conforme ella aullaba quedito, los restos de semen vidriado y del blancuzco líquido de su sexo mezclados e inferenciados, escurriéndose por sus muslos. (Arias, 2002, pp. 120-121)
\end{abstract}

Los deseos y las pasiones del cuerpo, sus formas y excresiones en este pasaje desplazan en importancia a los princinpios y las reglas revolucionarias. Mientras que la descripción de la escena sexual con Valéria Rodrigo la infunde de pasión, el mismo describe los principios revolucionarios en la ausencia de ella; para Rodrigo esos principios significaron una mera herramienta de sobrevivencia, una forma de "protección" que lo resguardaría de la "lluvia o de la muerte". Los representa entonces en pronunciamiento fríos, carentes de sentido, y como los describiera el mismo Rodrigo en otro lugar, en cifras "escritas por algún chaparro bigotudo sapurruco que no era sino una tuerca más en el vasto engranaje del desdén y deshumanización que era mi querida vanguardia, la arquitecta del hombre nuevo" (Arias, 2002, p. 138).

Estando en la guerrilla la pasión había que negarla o vertirla hacia la política, pues "No quedaba ni una esquinita oxidada para otro tipo" (Arias, 2002, p. 57). La narrativa y el texto mismo, o bien esta Sopa de caracol, cumple aquí entonces la función de un recipiente; un lugar donde el narrador derrama la pasión antes vedada; un lugar donde sí es posible hablar desde los sentidos que la razón de la guerrilla antes silenciara. La literatura del período revolucionario centroamericano recordemos, se mantuvo, como el militante, regida y hasta controlada por las viscicitudes de la guerra y la guerrilla. Como lo conceptualizara la misma revolución cubana durante aquella segunda mitad del siglo XX - dentro de la Revolución, todo; contra la Revolución, nada. Por ello es que a lo largo de esta obra de Arias la estética y corporalidad de la pasión se apoderan del lenguaje, de la trama, y del marco estructurador de narrativa misma: esa deliciosa sopa de caracol preparada.

A través de la pasión Rodrigo también quiebra la monotonía de la rutina diaria en el exilio, su insubstancial posición académica como empleado en una "universidad de tercera", y la soledad que lo asecha en San Francisco, California. La relación sexual que éste sostiene con su perra Amaranta por ejemplo, desborda en pasión en todo sentido. Representa además dentro del marco de la novela, aún otra forma de romper con esa mayor estructuración y "lógica" cartesiana:

Pero si entro en el teje y maneje del asunto es porque a pesar de que a lo hecho pecho, la Amaranta derivaba también placer del asunto [...] Lo que les cuento es hasta cierto punto una parábola aunque lo que se paraba no eran las bolas. Es una reminiscencia que refleja mis tensiones y ansiedades recubiertas de emociones aunque parezca a veces como si cavara mi propia tumba o me tendiera una trampa. Por lo menos puedo decir que no fui un observador pasivo de la vida sin propósito ni despropósito. Pasó entonces que entré por la puerta grande con Amaranta y fue grandioso por su deleite. Entendí con lágrimas en los ojos el porqué de la persistencia de la pasión. Era como sentir los movimientos rotatorios del agua en su lomo, temblando sobre un puente colgante a punto de romperse, pulida la congoja de dos seres que vivían 
languideciendo porque esperaban amar para poder perdurar. Quebramos el ambiente con nuestra propia música en la cual ladridos y aullidos se anudaron pulverizando juntos las paredes en su ascenso hasta las maltratadas capas del ozono desde donde anunciaron un nuevo amanecer cultural para la armoniosa fusión entre animal y hombre [...] Habría sido un matrimonio perfecto de no excedernos en el abuso de la pasión. (Arias, 2002, pp. 236-237)

La zoofilia o bestiliadad de Rodrigo podría a primera vista entenderse en la misma perspectiva del lente médico: un "trastorno de la salud mental"; "aberración" o "perversión sexual"; en "algunos casos", una "conducta sodomítica"; o en otros, "un instinto sexual degenerado o anormal” (Silva-Silva, 1995, p. 333). Podría incluso entenderse como la manipulación de un hombre sobre su perra. Pero si leemos esta relación perra-hombre desde la propuesta de rompimiento cartesiano y eurocéntrico que sabemos es uno de los objetivos principales del texto, considero que hallaremos una lectura mucho más reveladora.

La relación perra-hombre pervierte y subvierte la normalización de tecnologías de instrumentalización anudadas a la colonialidad del poder. Casi "perfecta" ("de no excedernos en el abuso de la pasión"), la relación carece de un tratamiento de sub-otredad vis-à-vis el otro. Altera el modelo inferioridad/superiordidad promovidas por la racionalización cartesiana, instaurándose en vez un modelo basado en relaciones horizontales de poder: "la Amaranta derivaba también placer del asunto", declara Rodrigo. Amaranta y Rodrigo dan y reciben (placer) equitativamente en esta relación mucho más inusual (Arias, 2002, p. 236). Ni uno da ni quita más que el otro. Al contrario, se establece una correspondencia sincrónica entre los dos, fundiéndose incluso los dos en uno mismo: "la armoniosa fusión entre animal y hombre" (Arias, 2002, p. 236).

Frente a la realidad de la omnipresente muerte experimentada durante la guerra y la guerrilla narrada por Rodrigo a lo largo de la novela (y la cena), el pasaje evoca también una actitud de sobrevivencia; un deseo de combatir la instransigencia de la muerte a través de la pasión. La frase "Vivían languideciendo porque esperaban amar para poder perdurar" proyecta un sí a la vida, suprime la realidad de muerte que el personaje nos viene narrando sobre el caso centroamericano, y propone una vía a través de la cual es posible su refutación: la pasión y sus desbordes. La relación con la perra es transgresora en este sentido. Cumple la función de transgredir los mismos límites de la pasión y así romper con las formas normalizadas del amar y del amor.

\section{Conclusión}

Como lo mencionara ya antes, tras haber saboreado la deliciosa cena y escuchado a lo largo de toda la noche las historias y reflexiones de Rodrigo, hacia el final de la novela sus invitados deciden que llegó el momento de tomar riendas sobre el asunto y deleitarse con un último platillo: será el principal de la noche. Con la canción de "Sopa de caracol" como ruido de fondo en la escena, los invitados detienen a Rodrigo y poco a poco le empiezan a quitar sus ropas y seguidamente a vestirlo de mujer. Las invitadas también se travisten, alistando el momento orgíastico que se avecina. Al darse cuenta de lo que empieza a suceder, Rodrigo nos dice:

\footnotetext{
Ayyyyy sí, qué rico. Seguí frotando suavecito, alrededor de la entrada al infierno, la caldera del diablo, apenas tocando la carnita suave de adentro con aceitito que calienta y excita, anagrama lujurioso que respinga las nalguitas, [...] ¡Ay! ¿Y eso? No me agarrés el pelo. Dejame levantar la cabeza. Se siente más grueso que un dedo, ay, más grueso, y sin el taco epidérmico. Más bien una cierta lisura plástica, ouch [...] Qué estás haciendo, me vas a partir en dos, cabrón de mierda! [...] Me voy a morir descuartizado [...] duele, arde como si me frotaras chile en la lengua, estás disipando mi identidad, atravesándome, descontinuándome... (Arias, 2002, pp. 277-278)
} 
Por medio del travestismo de los personajes vemos pues, disipsear las identidades de género y quebrantarse de una vez por todas la identidad del militante. Desvestirlo y revestirlo es aquí un acto simbólico de esa muerte identitaria que busca aniquilar por completo al sujeto militante que una vez promovió lógicas eurocentradas, heteronormativas, racistas y clasistas. Es la metáfora electa por el autor para la transfiguración del sujeto en la posguerra; es una forma de representar la necesidad de transformación y autoreflexión en la experiencia del ex-militante.

En estas últimas páginas de la novela además, el pene en lo particular aparece como un miembro sexual más de transgresión cartesiana. Aquí el mismo se ve reconfigurado por medio del lenguaje. El lenguaje lo presenta no como un órgano ligado al poder de la colonialidad, sino como un órgano maleable, transgresor de la razón, sin identidad fija, y como un órgano más que todo del placer:

\begin{abstract}
la punta, punta rítmica, punta que puya y exige, punta provocadora, punta prodigiosa, punta profesoral profundamente profética, punta profanadora, punta prometedora, punta proletaria, punta que pronostica la propagación de mi provisoria promiscuidad, punta propaladora del inquieto propileo de mi propiedad que propone prosaicamente el proscenio proscrito para proseguir protagonizando próteamente la protocolar prótasis que prostituye la razón. (Arias, 2002, p. 271)
\end{abstract}

Al reinterpretar el momento de la guerrilla revolucionaria a partir del cuerpo -revelar su sujeción vigilada dentro de la guerrilla y expresar su continua exposición a la muerte- en Sopa de caracol Arturo Arias logra una textualidad de sensibilidades otras. La voz narrativa asume la tarea de entrar en consciencia de la invisibilización y eliminación del sub-otro racializado y diferenciado, plasmando discursivamente lo que la crítica Modernidad/Colonialidad llamaría un grito de "horror ante el mundo de la muerte creado por la colonización" (Maldonado-Torres, 2008, p. 64). De hecho, la novela de Arias podría entenderse como un grito; uno que expresa un rotundo "ya basta" a las lógicas que colonializan el pensamiento y lo "revolucionario," invitándonos en vez a transfigurarlas a través de la celebración del placer en sus diversas posibilidades. El cuerpo instrumentalizado deja por lo tanto de reproducir prácticas de la colonialidad que lo han venido sumiendo a él y a sus semejantes en la invisibilidad y la muerte, y cumple en vez ahora una función de desobediencia. Esta desobediencia es la que ahora le potencia la vida al sujeto exmilitante en la diáspora y el exilio; o por lo menos la que le potencia la sobrevivencia.

\title{
Notas
}

1. Véase: Siu, O. M. (2013). Central American Enunciations from US Zones of Indifference, or the Sentences of Coloniality. Studies in 20th and 21st Century Literature. 37 (2), 1-17.

2. La Guerra Civil Guatemalteca concluye oficialmente en 1996.

\section{Bibliografía}

Agamben, G. (2003). Estado de Excepción. Homo sacer, II, I. Buenos Aires: Adriana Hidalgo Editora S. A.

Arias, A. (2002). Sopa de caracol. Guatemala Ciudad, Guatemala: Alfaguara.

Maldonado-Torres, N. (2008). La descolonización y el giro des-colonial. Tabula Rasa. 9, 61-72. http://www.revistatabularasa.org/numero-9/04maldonado.pdf [Consulta 11 de febrero de 2012]. 
Silva-Silva, H. (1995). Medicina legal y psiquiatría forense. Santiago de Chile: Editorial Jurídica de Chile.

Siu, O. M. (2013). Central American Enunciations from US Zones of Indifference, or the Sentences of Coloniality. Studies in 20th and 21st Century Literature. 37 (2), 1-17. 
